\title{
Estrutura espacial e diamétrica de espécies arbóreas e seus condicionantes em um fragmento de cerrado sentido restrito no sudoeste goiano
}

\author{
Wilson Pereira Bernasol ${ }^{1}$ e Matheus de Souza Lima-Ribeiro ${ }^{1,2}$ \\ Recebido: 07.05.2009; aceito: 15.04.2010
}

\begin{abstract}
Spatial distribution pattern and size structure of tree species and its structuring factors in a fragment of the Brazilian cerrado). The aim of this study was to analyze population structure and spatial distribution pattern of five tree species in a fragment of cerrado stricto sensu in the southwest of the Goiás State, Brazil. Fifty quadrats of $10 \times 10 \mathrm{~m}(100$ $\mathrm{m}^{2}$ ) were surveyed, and all individuals within each quadrat were sampled. The theoric distributions of Poisson and Negative Binomial and two indices of dispersion, the variance to mean ratio $(I)$ and the Green's coefficient $\left(I_{\mathrm{o}}\right)$, were used to detect the spatial pattern of the populations. The population structure was verified by the frequencies distribution of six size classes. An aggregated spatial pattern was detected for all species, with smaller individuals segregated spatially from bigger individuals, except for Qualea grandiflora Mart., and also the distribution of size classes in "reverse J-shaped", but with many particularities. This suggests differences in the structural pattern of the populations investigated and, consequently, in its dynamics and structuring processes.
\end{abstract}

Key words: aggregated distribution, population structure, recruitment, reverse J-shaped

RESUMO - (Estrutura espacial e diamétrica de espécies arbóreas e seus condicionantes em um fragmento de cerrado sentido restrito no sudoeste goiano). O objetivo deste estudo foi verificar o padrão espacial e a estrutura populacional de cinco espécies arbóreas em um fragmento de cerrado sentido restrito no município de Jataí, sudoeste goiano. Foram demarcadas 50 parcelas de $10 \times 10 \mathrm{~m}\left(100 \mathrm{~m}^{2}\right)$ e amostrados todos os indivíduos dentro de cada parcela. Para detectar o padrão espacial da população, foram utilizadas as distribuições teóricas de Poisson e Binomial Negativa e dois índices de dispersão: a razão variância/média $(I)$ e o coeficiente de Green $\left(I_{g}\right)$. A estrutura diamétrica foi verificada pela distribuição de frequências de seis classes de tamanho. As espécies apresentaram distribuição espacial agregada, com os indivíduos menores espacialmente disjuntos dos maiores, com exceção de Qualea grandiflora Mart., e distribuição diamétrica em forma de "J-invertido", embora que com algumas peculiaridades. Isso sugere diferenças no padrão estrutural das cinco populações estudadas e, consequentemente, nos processos de estruturação e dinâmica de cada espécie.

Palavras-chave: distribuição agregada, estrutura populacional, J-invertido, recrutamento

\section{Introdução}

O bioma Cerrado é constituído por um conjunto de fitofisionomias determinadas pela ação do fogo, clima, disponibilidade de água e nutrientes, topografia, latitude e o substrato onde se desenvolvem (Ribeiro \& Walter 1998). Além disso, a localização geográfica do Cerrado propicia seu contato com praticamente todos os grandes biomas do continente sul americano, fazendo com que essa região apresente uma paisagem com inclusões de formações florestais em meio a formações savânicas e campestres, ocorrendo assim, uma enorme variação fitofisionômica em escalas espaciais diversas devido aos fatores heterogêneos presentes no ambiente (Eiten 1994, Oliveira Filho \& Ratter 2002).

Dessa forma, este bioma é oportuno para a realização de variados estudos nos vários campos

1. Universidade Federal de Goiás, Campus Jataí, Coordenação de Ciências Biológicas, Rua Riachuelo 1.530, Setor Samuel Graham, 75.804-020 Jataí, GO, Brasil.

2. Autor para correspondência: paleo_ribeiro@yahoo.com.br 
das ciências naturais, inclusive em ecologia. Apesar de vários estudos de ecologia serem realizados no Planalto Central brasileiro, poucos trabalhos estão relacionados à estrutura populacional e distribuição espacial das espécies vegetais do Cerrado (Hay et al. 2000, Souza \& Coimbra 2005), especialmente no sudoeste goiano (Lima-Ribeiro 2007a, b, LimaRibeiro \& Prado 2007). Muitos estudos em ecologia vegetal têm usado a análise espacial para detectar padrões em comunidades vegetais e entender a distribuição dos indivíduos e sua relação com os fatores que influenciam a estruturação populacional (Fortin et al. 2002).

Os indivíduos em uma população podem apresentar três padrões básicos de distribuição espacial: aleatório, agrupado e uniforme (Ludwig \& Reynolds 1988, Krebs 1999). O padrão aleatório, em que a localização de um indivíduo não interfere na localização de outro da mesma espécie, se opõem ao padrão de distribuição agrupado (ou agregado), em que a presença de um recurso (e.g. tipo de solo) tem alta probabilidade de influenciar a localização dos indivíduos de uma mesma espécie, apresentando, assim, baixos índices de dispersão. No padrão de distribuição uniforme (ou regular), a população apresenta alto índice de dispersão e os indivíduos possuem distâncias semelhantes uns dos outros (Greig-Smith 1964, Kershaw 1973, MuellerDombois \& Ellenberg 1974, Barbour et al. 1987).

Apesar da possibilidade de uma população apresentar distribuição uniforme, as plantas raramente se distribuem dessa maneira na natureza (Barbour et al. 1987). De acordo com Legendre \& Fortin (1989), os seres vivos, em geral, tendem a se distribuir de forma agrupada devido ao ambiente ser estruturado espacialmente por várias formas de produção de energia, gerando assim processos irregulares de disponibilização de recursos. Dessa forma, os processos demográficos (e.g. natalidade, mortalidade e migração) são influenciados pela heterogeneidade ambiental, gerando padrões espaciais que se distanciam da aleatoriedade e/ou uniformidade (Thomas \& Kunin 1999).

No Cerrado brasileiro, várias espécies vegetais tem mostrado um padrão de distribuição espacial agregado em diferentes escalas e localidades (Oliveira et al. 1989, Meireles \& Luiz 1995, Hay et al. 2000, Resende et al. 2003, Monteiro \& Fisch 2005, Souza \& Coimbra 2005, Lima-Ribeiro, 2007a, b, Lima-Ribeiro \& Prado 2007). Este padrão de distribuição parece ser predominante entre as espécies arbóreo-ar- bustivas dos cerrados, indicando semelhanças entre os processos de estruturação e dinâmica populacional ocorrentes nas savanas em geral, onde a estrutura espacial dominante das espécies vegetais também é agregada, como descrito por San Jose et al. (1991) para espécies arbóreas dos Llanos venezuelanos.

Os vegetais normalmente se distribuem de forma agregada por serem estruturados, principalmente, pelos fatores abióticos como textura, fertilidade e disponibilidade hídrica do solo, luminosidade, temperatura, entre outros, que são diretamente influenciados pelas variações na produção e disponibilização de energia (Barbour et al. 1987). Os fatores bióticos (competição e herbivoria), apesar de influenciados indiretamente pela produção de energia, bem como pelos distúrbios naturais e antrópicos, também influenciam o padrão espacial e a dinâmica das populações vegetais (Thomas \& Kunin 1999).

Além disso, a variação de tamanho dos indivíduos em uma população vegetal também é resultado da ação de vários fatores bióticos e abióticos (Hutchings 1997). Estruturas de tamanho têm sido utilizadas na literatura como critério para a classificação das espécies em grupos ecológicos (Barbour et al. 1987). A estrutura de tamanho mais comumente registrada em espécies arbóreas é a do tipo "J-invertido", com muitos indivíduos nas menores classes de tamanho que, individualmente, representam uma pequena parte do total da biomassa da população e poucos indivíduos nas classes superiores, que individualmente representam uma grande parte da biomassa total da população (Barbour et al. 1987).

Esse tipo de estrutura de tamanho é muitas vezes interpretado como um indicador de estabilidade ou incremento da população e capacidade de autoregeneração e reprodução sob o dossel, enquanto as estruturas em formato de "sino" indicam espécies que não se reproduzem com frequência sob o dossel e que necessitam da abertura de clareiras para regeneração (Barbour et al. 1987, Felfili \& Silva Júnior 1988, Silva Júnior \& Silva 1988). Entretanto, levando em consideração que em áreas de cerrado sentido restrito a luz provavelmente não seja um fator limitante para o estabelecimento de novos indivíduos, o uso desta classificação não é adequado (Virillo 2006). Além disso, as estruturas de tamanho observadas parecem não ser relacionadas a grupos ecológicos e sim a outros fatores, como a predação de sementes e competição (Virillo 2006).

Assim, o presente estudo tem por objetivo identificar e analisar a estrutura populacional e o 
padrão de distribuição espacial de cinco espécies arbóreas em uma área de cerrado sentido restrito no município de Jataí, sudoeste do estado de Goiás, Brasil.

\section{Material e métodos}

Descrição da área de estudo - A área de estudo está inserida na Reserva Biológica do $41^{\circ}$ Batalhão de Infantaria Motorizado do Exército Brasileiro ( $41^{\circ}$ BIMtz), localizada próxima à área urbana da cidade de Jataí, sudoeste do estado de Goiás, Brasil, entre as coordenadas $17^{\circ} 52^{\prime} 52^{\prime \prime}-17^{\circ} 54^{\prime} 58^{\prime \prime}$ de latitude Sul e $51^{\circ} 39^{\prime} 43^{\prime \prime}-51^{\circ} 43^{\prime} 06^{\prime}$ 'de longitude Oeste. Os cerrados, em geral, caracterizam-se por apresentar um clima com duas estações bem definidas: inverno seco e verão chuvoso. A estação seca ocorre de maio a setembro, com precipitação e temperatura média anual de $1.500 \mathrm{~mm}$ e $25^{\circ} \mathrm{C}$, respectivamente (Nimer 1989). A região apresenta pedologia caracterizada por Latossolos Vermelho-Escuros, os quais ocorrem sobre a zona de contato entre a cobertura terciária e o arenito do Grupo Bauru (Mariano \& Scopel 2001), com um relevo variando entre 650 e 850 metros de altitude.

$\mathrm{Na}$ área de estudo encontra-se uma vegetação típica de cerrado sentido restrito por apresentar árvores baixas, inclinadas, tortuosas, com ramificações irregulares e retorcidas e formação de dossel aberto (Ribeiro \& Walter 1998). Os arbustos e subarbustos encontram-se espalhados e, geralmente, com evidências de queimadas. A Reserva Biológica do $41^{\circ}$ BIMtz possui um histórico de uso do solo por atividades agropecuárias, porém, desde a década de 1960 a área encontra-se protegida pelo exército brasileiro. No entanto, as queimadas são frequêntes e concentram-se no período de seca. Regionalmente, a vegetação encontra-se bastante degradada devido à ação antrópica, principalmente pela formação de pastagens com gramíneas invasoras do gênero Brachiaria spp. e cultivos de soja e milho.

Descrição das espécies - Foram consideradas, nesse estudo, cinco espécies arbóreas abundantes na Reserva Biológica do $41^{\circ}$ BIMtz, dentre elas: Butia purpurascens Glassman (Arecaceae), Curatella americana L. (Dilleniaceae), Piptocarpha rotundifolia (Less.) Baker (Asteraceae), Qualea grandiflora Mart. (Vochysiaceae) e Qualea multiflora Mart. (Vochysiaceae).

Butia purpurascens é uma palmeira que apresenta estipe único, podendo chegar até os quatro metros de altura. Suas folhas são fortemente arqueadas e as raques não apresentam espinhos. A planta é monóica, com inflorescências unissexuais, masculinas ou femininas, sobre um mesmo indivíduo. Os frutos são ovóides, de cor amarelada ou arroxeada com mesocarpo suculento e aromático, muito apreciado pela fauna regional e pelo homem (Lorenzi 1996).

Curatella americana é uma árvore semidecídua, característica de terrenos secos do Cerrado, com altura de seis a dez metros e tronco curto de 40 a 50 $\mathrm{cm}$ de diâmetro. Apresenta dispersão descontínua, ocorrendo em grandes populações em determinadas áreas e faltando completamente em outras. Produz anualmente grande quantidade de sementes, sendo os seus frutos avidamente procurados por pássaros durante a maturação. Suas folhas são altamente silicosas e ásperas, o que permitiu no passado seu uso para lixar madeira (Lorenzi 2000a).

Piptocarpha rotundifolia é uma árvore pequena, que apresenta indivíduos com altura de quatro a oito metros, com tronco tortuoso de 15 a $25 \mathrm{~cm}$ de diâmetro, folhas simples e alternas. Ocorre com exclusividade nos cerrados, onde é abundante, porém com padrão de dispersão descontínuo e irregular, além de ocorrer em formações secundárias (Lorenzi 1998).

Qualea grandiflora é uma planta decídua, característica de cerradão e transições para cerrado sentido restrito, sendo encontrada geralmente em terrenos altos, secos e bem drenados. É a espécie mais bem distribuída no Cerrado. Possui altura de sete a 12 metros, com tronco de 30 a $40 \mathrm{~cm}$ de diâmetro, folhas simples, opostas, rígidas de dez a $14 \mathrm{~cm}$ de comprimento. Ocorre tanto em formações primárias como secundárias, com alta frequência de indivíduos (Ratter et al. 2003). Produz, anualmente, grande quantidade de sementes que são dispersas pelo vento (Lorenzi 1998).

Qualea multiflora é uma árvore pioneira, exclusiva do cerrado sentido restrito e campo-sujo, onde ocorre com elevada frequência, porém bastante descontínua e em solos de baixa fertilidade. Possui altura de quatro a seis metros, tronco geralmente tortuoso, folhas simples e opostas e rebrota com facilidade após a queima. Produz anualmente moderada quantidade de sementes, prontamente disseminadas pelo vento (Lorenzi 2000b).

Com exceção de B. purpuracens, palmeira endêmica do sudoeste goiano (Lorenzi 1996), as demais espécies são típicas do Cerrado, comumente encontradas em cerrado sentido restrito (Ratter et al. 2003). 
Coleta dos dados - Foram demarcadas 50 parcelas de $10 \times 10 \mathrm{~m}\left(100 \mathrm{~m}^{2}\right)$, totalizando 5.000 $\mathrm{m}^{2}$ de área amostrada. As parcelas foram dispostas de forma contígua (método proposto por GreigSmith 1964), divididas em dez linhas com cinco unidades amostrais cada, formando um bloco de $50 \times 100$ metros. Em cada parcela, foram contados todos os indivíduos das espécies $B$. purpurascens, C. americana, $P$. rotundifolia, $Q$. grandiflora e $Q$. multiflora, e tomadas as medidas de altura da planta e da circunferência do caule ao nível do solo. A altura foi estimada por comparação com vara graduada de dois metros de comprimento, disposta paralelamente aos indivíduos e a circunferência do caule foi mensurada diretamente ao nível do solo com fita métrica. No Cerrado, a circunferência do caule é tomada, normalmente, ao nível do solo para que a medida seja coletada abaixo da região de perfilhamento (Barreira et al. 2002). Para B. purpurascens, a altura dos indivíduos foi medida da base até o ponto de abertura das folhas apicais e a circunferência do caule ao nível do solo para os indivíduos com estipe exposto. No caso de indivíduos com estipe não exposto, foi tomada a circunferência da base do estipe, também ao nível do solo.

Para verificar a influência do substrato na distribuição espacial dos indivíduos, foram coletadas seis amostras superficiais de solo $(0-20 \mathrm{~cm})$ em pontos distintos na área amostrada e realizadas análises químicas (macronutrientes) e texturais. A seleção dos pontos para amostragem do solo ocorreu após a identificação do padrão de distribuição espacial das cinco espécies analisadas. Assim, as amostras foram coletadas em pontos dentro e entre agregados para que fosse possível verificar a influencia do substrato na distribuição espacial dos indivíduos.

Análise dos dados - Para identificar a estrutura espacial da população, a distribuição de frequências observadas $\left(\mathrm{n}^{\mathrm{o}}\right.$. de parcelas com $0,1,2, \ldots, r$ indivíduos) foi comparada com distribuições teóricas. Os modelos teóricos utilizados para calcular as frequências esperadas e, conseqüentemente, testar as hipóteses de distribuição espacial aleatória e agregada foram a Distribuição de Poisson (Greig-Smith 1964) e a Distribuição Binomial Negativa (Ludwig \& Reynolds 1988, Krebs 1999), respectivamente. Caso a distribuição de frequências observadas não se ajustasse a nenhum desses dois modelos, a hipótese de distribuição uniforme seria testada pela Distribuição Binomial Positiva, conforme metodologia adotada por Ludwig \& Reynolds (1988) e Krebs (1999).
A significância estatística foi verificada através do teste qui-quadrado $\left(\chi^{2}\right)$ ao nível de significância de 5\% (Ludwig \& Reynolds 1988, Krebs 1999). Durante o cálculo do qui-quadrado, as frequências esperadas menores que dois e suas respectivas frequências observadas foram somadas, minimizando, assim, a probabilidade de erro Tipo I. A comparação entre frequências (observadas e esperadas) muito baixas, afeta a estimativa da probabilidade do teste de significância (neste caso o qui-quadrado) por inflar o erro Tipo I, fazendo-nos rejeitar a hipótese nula mais vezes do que se espera pelo nível de significância adotado (Sokal \& Rohlf 1995, Krebs 1999, Zar 1999).

Para o cálculo do índice de dispersão dos indivíduos foram utilizados a razão variância/média (I) e o coeficiente de Green ( $I g$ ), que mostram o quão agrupados os indivíduos se encontram na população. Valores de $I$ e $I g$ iguais a um e zero, respectivamente, indicam um padrão de distribuição espacial aleatória para a população. Valores menores indicam distribuição uniforme e valores maiores, distribuição agregada (Ludwig \& Reynolds 1988, Krebs 1999).

Para identificar a estrutura de tamanho da população, os indivíduos foram divididos em seis classes de acordo com a circunferência do caule ao nível do solo, as quais foram ajustadas ao modelo "J-invertido" (ou exponencial negativo, y = e-x) por regressão linear simples (Sokal \& Rohlf 1995, Zar 1999). Foram também calculados os coeficientes "q"de Liocourt para analisar a relação mortalidade/ crescimento dos indivíduos por meio de classes diamétricas (Meyer 1952, Meyer et al. 1961).

A amplitude das classes variou entre as espécies e foi estimada utilizando-se a média e o desvio padrão da circunferência do caule dos indivíduos, conforme mostrado na tabela 1. Segundo Bongers et al. (1988), não é muito acurado usar classes uniformes para a construção dos diagramas de frequência quando se deseja comparar estruturas de tamanho entre espécies diferentes, já que isso resulta em uma diferenciação entre espécies com portes diferentes ao invés de diferenciar espécies com estruturas de tamanho diferentes.

A análise de correlação foi utilizada para testar a relação entre a circunferência do caule e altura da planta para cada população e os resíduos dessa relação foram utilizados para verificar as discrepâncias entre as duas variáveis no conjunto de indivíduos. Para isso, foi calculado o desvio padrão separadamente dos resíduos oriundos dos pontos acima e abaixo do ajuste linear para as cinco populações estudadas. 
Tabela 1. Critérios usados para o cálculo da amplitude das classes de tamanho para as cinco espécies arbóreas do cerrado sentido restrito estudadas no $41^{\circ}$ BIMtz, Jataí, Goiás, Brasil. C = circunferência do caule ao nível do solo.

Table 1. Criteria to calculate the amplitude of the size classes for tree species of Cerrado sensu stricto analysed in the $41^{\circ}$ BIMtz, Jataí, Goiás, Brazil. $\mathrm{C}=$ stem circumference at ground level.

\begin{tabular}{l|l}
\hline Classes diamétricas & \multicolumn{1}{c}{ Amplitude } \\
\hline Classe 1 & $\mathrm{C}<$ média $-0,5^{*}$ desvio padrão \\
Classe 2 & média $-0,5^{*}$ desvio padrão $<\mathrm{C}<$ média \\
Classe 3 & média $<\mathrm{C}<$ média $+0,5^{*}$ desvio padrão \\
Classe 4 & média $+0,5^{*}$ desvio padrão $<\mathrm{C}<$ média + desvio padrão \\
Classe 5 & média + desvio padrão $<\mathrm{C}<$ média $+1,5^{*}$ desvio padrão \\
Classe 6 & $\mathrm{C}>$ média $+1,5^{*}$ desvio padrão \\
\hline
\end{tabular}

O teste "t" bi-caudal foi utilizado para comparar as médias de densidade e da circunferência do caule das cinco espécies ao nível de significância de 5\% (Sokal \& Rohlf 1995, Zar 1999).

Para verificar a associação espacial dos indivíduos entre as diferentes classes de tamanho dentro e entre espécies, a frequência de indivíduos em cada classe diamétrica foi ordenada pela Análise de Componentes Principais (Valentin 2000), considerando cada população separadamente e o conjunto total de populações (das cinco espécies), respectivamente. A mesma ordenação foi realizada considerando a frequência de indivíduos das cinco espécies em cada classe diamétrica e os valores absolutos dos elementos indicativos da fertilidade do solo (concentração de Al, Ca, Mg, K, P, Acidez - pH, Matéria Orgânica - MO, Soma de Bases Trocáveis - SB, Capacidade de Troca de Cátions - CTC e Saturação por Bases - V\%). Essa técnica permite analisar a associação dos indivíduos em diferentes classes de tamanho entre si e com o ambiente (neste caso, as parcelas).

\section{Resultados}

Estrutura diamétrica das populações - Os resultados mostraram diferenças significativas quanto à circunferência do caule e a amplitude das classes de tamanho para as populações analisadas. B. purpurascens apresentou os indivíduos com caules significativamente mais espessos, enquanto Q. multiflora apresentou os indivíduos com menor circunferência de caule. As demais espécies apresentaram médias da circunferência do caule semelhantes entre si (figura 1). O mesmo padrão também foi observado para a amplitude das classes de tamanho (tabela 2).

As cinco espécies apresentaram distribuição de frequência das classes diamétricas em forma de "J-invertido", com valores expressivos dos coeficientes de determinação em relação ao ajuste exponencial negativo, exceto para B. purpurascens e $P$. rotundifolia (figura 2), porém, com estruturas irregulares verificadas pela variação nos valores do coeficiente "q" de Liocourt ao longo das últimas cinco classes de tamanho.

Tabela 2. Amplitude das seis classes de tamanho (circunferência do caule ao nível do solo) para as cinco espécies arbóreas do cerrado sentido restrito estudadas no $41^{\circ}$ BIMtz, Jataí, Goiás, Brasil. Os critérios para delimitação das classes estão estabelecidos na tabela 1.

Table 2. Amplitude of the six size classes (stem circumference at ground level) for tree species of Cerrado sensu stricto analysed in the $41^{\circ}$ BIMtz, Jataí, Goiás, Brazil. The criteria to delineate the size classes are established in the table 1.

\begin{tabular}{|c|c|c|c|c|c|}
\hline & $\begin{array}{c}\text { Butia } \\
\text { purpurascens }\end{array}$ & $\begin{array}{c}\text { Curatella } \\
\text { americana }\end{array}$ & $\begin{array}{l}\text { Piptocarpha } \\
\text { rotundifolia }\end{array}$ & $\begin{array}{c}\text { Qualea } \\
\text { grandiflora }\end{array}$ & $\begin{array}{c}\text { Qualea } \\
\text { multiflora }\end{array}$ \\
\hline Classe $1(\mathrm{~cm})$ & $<20$ & $<11$ & $<11$ & $<9$ & $<7$ \\
\hline Classe $2(\mathrm{~cm})$ & 21 a 34 & 12 a 21 & 12 a 21 & 10 a 19 & 8 a 13 \\
\hline Classe $3(\mathrm{~cm})$ & 35 a 48 & 22 a 31 & 22 a 31 & 20 a 29 & 14 a 18 \\
\hline Classe $4(\mathrm{~cm})$ & 49 a 62 & 32 a 41 & 32 a 41 & 30 a 39 & 19 a 24 \\
\hline Classe $5(\mathrm{~cm})$ & 63 a 76 & 42 a 51 & 42 a 51 & 40 a 49 & 25 a 29 \\
\hline Classe $6(\mathrm{~cm})$ & $>76$ & $>52$ & $>52$ & $>50$ & $>30$ \\
\hline
\end{tabular}


No entanto, $C$. americana e $Q$. multiflora apresentaram um decréscimo mais uniforme do número de indivíduos entre as diferentes classes de tamanho, conforme os coeficientes "q" de Liocourt (figura 2b, d), indicando distribuição diamétrica tendendo a balanceada ou mais balanceada que a das demais espécies. Q. grandiflora apresentou uma variação ao modelo da estrutura em forma de "J-invertido", em que o número de indivíduos na primeira classe de tamanho é inferior à segunda classe (figura 2c). No entanto, o decréscimo uniforme na frequência das classes posteriores, verificada pelos valores do coeficiente " $\mathrm{q}$ " de Liocourt, e o elevado coeficiente de determinação ao ajuste exponencial negativo (figura 2c), indicam que a distribuição diamétrica dessa espécie também tende ao equilíbrio quando analisada no geral, embora com sinais de irregularidade.

Ao contrário, B. purpurascens e $P$. rotundifolia apresentaram os mais baixos coeficientes de determinação ao ajuste exponencial negativo e variações consideráveis ao modelo "J-invertido", expressadas pela diferença abrupta na frequência das duas primeiras classes de tamanho e pelas oscilações (alta e queda) na frequência das classes intermediárias e superiores (figuras $2 \mathrm{a}, \mathrm{e}$ ). Portanto, $B$. purpurascens e $P$. rotundifolia apresentam distribuições diamétricas não balanceadas e mais irregulares quando comparadas com $C$. americana, $Q$. multiflora e $Q$. grandiflora.

Foram registrados altos índices de correlação entre a circunferência do caule e a altura da planta para as cinco espécies analisadas (figura 3), porém, com algumas variações extremas ("outliers") ao ajuste linear. C. americana apresentou alguns indivíduos com elevada altura, porém com caules relativamente finos, representados por pontos distantes e acima do ajuste linear (figura 3b), o que confere valor mais elevado para o desvio padrão dos resíduos acima do ajuste linear em relação aos resíduos abaixo do mesmo. O oposto é observado para $P$. rotundifolia, em que alguns indivíduos apresentaram valores elevados para a circunferência do caule, mas não para a altura da planta, representados por pontos distantes e abaixo do ajuste linear e conferidos pelo elevado desvio padrão de seus resíduos (figura 3e). Q. grandiflora e Q. multiflora apresentaram indivíduos com variações extremas nos dois sentidos, ou seja, valores elevados e equivalentes dos desvios padrão acima e abaixo do ajuste linear (figura $3 \mathrm{c}, \mathrm{d}$ ), enquanto os indivíduos de $B$. purpurascens apresentaram distribuição mais próxima do ajuste linear na relação circunferência do caule $v s$. altura da planta, ou seja, valores baixos e equivalentes dos desvios padrão acima e abaixo do ajuste linear (figura 3a).

Distribuição espacial dos indivíduos - Foram encontrados, no total, 549 indivíduos das cinco espécies nas 50 parcelas distribuídas pelos 5.000 $\mathrm{m} 2$ de área amostrada. A densidade de indivíduos variou consideravelmente entre as espécies, sendo que $Q$. multiflora e B. purpurascens apresentaram os maiores e menores valores, respectivamente (tabela 3). $P$. rotundifolia é a espécie que apresentou o maior número de indivíduos em uma única parcela (21 ind.), seguida de $Q$. multiflora (15 ind.), porém, todas as espécies apresentaram-se ausentes em algumas parcelas (tabela 3), embora as parcelas com densidade nula não sejam as mesmas para as cinco espécies.

As cinco populações analisadas apresentaram estrutura espacial agregada na área de estudo, uma vez que as frequências observadas ajustam-se, significativamente, às frequências esperadas pela

Tabela 3. Número total de indivíduos, média, variância e amplitude (mínimo e máximo) de indivíduos por parcela para as cinco espécies arbóreas do cerrado sentido restrito estudadas no $41^{\circ}$ BIMtz, Jataí, Goiás, Brasil. Médias seguidas de mesma letra não se diferem ao nível de significância de $5 \%$ pelo teste " $t$ ".

Table 3. Total number of individuals, mean, variance and amplitude (minimum and maximum) of individuals by quadrat for tree species of Cerrado sensu stricto analysed in the $41^{\circ}$ BIMtz, Jataí, Goiás, Brazil. Means with same letters not differ at significance level of 5\% by " $t$ " test.

\begin{tabular}{lcccc}
\hline \multirow{2}{*}{ Espécies } & \multirow{2}{*}{$\begin{array}{c}\text { No ind. } \\
\text { total }\end{array}$} & \multicolumn{3}{c}{ Densidade (ind./parcela) } \\
\cline { 3 - 5 } & 25 & Média & Variância & Amplitude \\
\hline B. purpurascens & $25,5 \mathrm{a}$ & 1,32 & $0-7$ \\
C. americana & 127 & $2,54 \mathrm{~b}$ & 6,58 & $0-10$ \\
P. rotundifolia & 120 & $2,58 \mathrm{~b}, \mathrm{c}$ & 12,16 & $0-21$ \\
Q. grandiflora & 75 & $1,5 \mathrm{c}$ & 3,60 & $0-7$ \\
Q. multiflora & 202 & $4,04 \mathrm{~d}$ & 7,26 & $0-15$ \\
\hline \multicolumn{1}{c}{ Total } & 549 & & & \\
\hline
\end{tabular}


Distribuição Binomial Negativa (tabela 4). Os índices de dispersão também confirmam essa hipótese, uma vez que os valores encontrados são significativamente maiores que um e zero para $I$ e $I g$, respectivamente (tabela 5).

A ordenação multivariada (PCA) mostra que os indivíduos de $B$. purpurascens, C. americana e $Q$. multiflora das classes diamétricas inferiores (classes 1 e 2) e superiores (classe 6) apresentamse estruturados espacialmente de forma disjunta entre si e dos indivíduos das classes diamétricas intermediárias (classes 3, 4 e 5, figuras 4a, b, d). $P$. rotundifolia apresenta um padrão semelhante para os indivíduos das classes diamétricas inferiores e superiores, porém, os indivíduos das classes diamétricas intermediárias não se encontram estruturados separadamente dos indivíduos menores (figura 4e). Apenas Q. grandiflora não apresenta esse padrão de estrutura espacial entre as classes de tamanho, em que tanto os indivíduos menores quanto os maiores apresentam-se associados à parcelas espacialmente próximas (figura 4c).
A PCA indica ainda, uma associação espacial entre os indivíduos jovens e adultos de $C$. americana e das duas espécies do gênero Qualea (figura 5). A ordenação realizada através da Análise de Componentes Principais para todas as classes diamétricas das cinco espécies sugere que os indivíduos menores (classes 1, 2 e 3 ) de C. americana encontram-se espacialmente associados com os indivíduos maiores (classe 6) de $Q$. grandiflora e $Q$. multiflora e vice-versa (figura 5). A mesma ordenação indica ainda que os indivíduos menores (classes 1, 2 e 3 ) de $P$. rotundifolia tendem a ocorrer espacialmente isolados das outras quatro espécies (figura 5).

Outro padrão observado é a tendência da maioria dos indivíduos das cinco espécies ocorrerem nas parcelas cujas amostras de solo demonstram menores teores de nutrientes (figura 6). A análise do solo indica baixa fertilidade do substrato e elevados teores de alumínio, além de textura argilosa para as seis amostras (tabela 6). No entanto, a amostra 1 evidencia melhores condições de fertilidade em relação às demais, com aparentes concentrações

Tabela 4. Teste de aderência (qui-quadrado) entre as frequências (parcelas com $0,1,2, \ldots, \mathrm{r}$ indivíduos) observadas e esperadas pela Distribuição de Poisson e Distribuição Binomial Negativa para as cinco espécies arbóreas do cerrado sentido restrito estudadas no $41^{\circ}$ BIMtz, Jataí, Goiás, Brasil.

Table 4. Chi-square test between frequencies observed (quadrats with $0,1,2, \ldots, \mathrm{r}$ individuals) and expected by Poisson' and Negative Binomial' distributions for tree species of Cerrado sensu stricto analysed in the $41^{\circ}$ BIMtz, Jataí, Goiás, Brazil.

\begin{tabular}{lccccccc}
\hline \multirow{2}{*}{ Espécies } & \multicolumn{3}{c}{ Poisson } & & \multicolumn{3}{c}{ Binomial Negativa } \\
\cline { 2 - 4 } \cline { 7 - 8 } & $\chi^{2}$ & G.l. & $p$ & & $\chi^{2}$ & G.l. & $p$ \\
\hline B. purpurascens & 5,00 & 2 & $<0,001$ & & 1,31 & 1 & 0,25 \\
C. americana & 28,97 & 5 & $<0,001$ & & 4,77 & 5 & 0,44 \\
P. rotundifolia & 20,88 & 5 & $<0,001$ & & 7,23 & 4 & 0,12 \\
Q. grandiflora & 32,07 & 4 & $<0,001$ & & 4,87 & 5 & 0,43 \\
Q. multiflora & 14,01 & 7 & $<0,001$ & & 11,63 & 6 & 0,07 \\
\hline
\end{tabular}

Tabela 5. Índices de dispersão para as cinco espécies arbóreas do cerrado sentido restrito estudadas no $41^{\circ}$ BIMtz, Jataí, Goiás, Brasil. Table 5. Dispersion indices for tree species of Cerrado sensu stricto analysed in the $41^{\circ}$ BIMtz, Jataí, Goiás, Brazil.

\begin{tabular}{lllllllc}
\hline \multirow{2}{*}{ Espécie } & \multicolumn{3}{c}{ Razão } & & \multicolumn{2}{c}{ Índice de Green } \\
\cline { 2 - 4 } \cline { 7 - 8 } & $I$ & $d$ & $p$ & & $I_{g}$ & $p$ \\
\hline B. purpurascens & 2,63 & 1,63 & $<0,05$ & & 0,110 & $<0,05$ \\
C. americana & 2,59 & 9,85 & $<0,05$ & & 0,078 & $<0,05$ \\
P. rotundifolia & 4,72 & 11,04 & $<0,05$ & & 0,032 & $<0,05$ \\
Q. grandiflora & 2,40 & 5,49 & $<0,05$ & & 0,019 & $<0,05$ \\
Q. multiflora & 1,80 & 3,42 & $<0,05$ & & 0,004 & $<0,05$ \\
\hline
\end{tabular}


Tabela 6. Características físicas (textura) e químicas (fertilidade) em seis amostras de solo coletadas em uma área de cerrado sentido restrito no $41^{\circ}$ BIMtz, Jataí - GO.

Table 6. Fisical (texture) and chemical (fertility) characteristics on the six ground samples of Cerrado sensu stricto in the $41^{\circ}$ BIMtz, Jataí, Goiás, Brazil.

\begin{tabular}{|c|c|c|c|c|c|c|c|c|c|}
\hline \multirow{2}{*}{ Amostra } & \multirow{2}{*}{$\begin{array}{c}\mathrm{pH} \\
\left(\mathrm{H}_{2} \mathrm{O}\right)\end{array}$} & \multicolumn{3}{|c|}{$\left(\mathrm{Cmolc} / \mathrm{dm}^{3}\right)$} & & \multicolumn{2}{|c|}{$\left(\mathrm{mg} / \mathrm{dm}^{3}\right)$} & \multicolumn{2}{|r|}{$(\mathrm{g} / \mathrm{kg})$} \\
\hline & & $\mathrm{Al}$ & $\mathrm{Ca}$ & $\mathrm{Mg}$ & & K & $\mathrm{P}$ & \multicolumn{2}{|r|}{ MO } \\
\hline 1 & 6,08 & 0,55 & 0,55 & 1,03 & & 57,72 & 0,88 & \multicolumn{2}{|r|}{60,58} \\
\hline 2 & 5,78 & 0,78 & 0,14 & 0,70 & & 43,68 & 0,69 & \multicolumn{2}{|r|}{46,25} \\
\hline 3 & 5,67 & 0,75 & 0,06 & 0,50 & & 22,50 & 0,47 & \multicolumn{2}{|r|}{39,56} \\
\hline 4 & 5,52 & 0,76 & 0,09 & 0,48 & & 24,00 & 0,47 & \multicolumn{2}{|r|}{44,48} \\
\hline 5 & 5,51 & 0,71 & 0,04 & 0,52 & & 25,50 & 0,55 & \multicolumn{2}{|r|}{44,79} \\
\hline 6 & 5,37 & 0,99 & 0,03 & 0,53 & & 28,50 & 0,51 & & \\
\hline \multirow[b]{2}{*}{ Amostra } & \multicolumn{3}{|c|}{$\left(\mathrm{Cmolc} / \mathrm{dm}^{3}\right)$} & \multicolumn{6}{|c|}{ Análise textural (\%) } \\
\hline & SB & CTC & V\% & & $\begin{array}{l}\text { Areia } \\
\text { grossa }\end{array}$ & & & Silte & Argila \\
\hline 1 & 1,73 & 8,01 & 21,58 & & 1,40 & & & 27,66 & 66,01 \\
\hline 2 & 0,95 & 7,03 & 13,54 & & 1,21 & & & 28,07 & 65,90 \\
\hline 3 & 0,62 & 6,93 & 8,92 & & 1,56 & & & 26,94 & 66,93 \\
\hline 4 & 0,63 & 6,19 & 10,20 & & 1,41 & & & 27,35 & 64,70 \\
\hline 5 & 0,63 & 6,07 & 10,31 & & 1,39 & & & 27,07 & 64,96 \\
\hline 6 & 0,63 & 7,06 & 8,96 & & 1,14 & & & 27,00 & 66,48 \\
\hline
\end{tabular}

superiores de macronutrientes $(\mathrm{Ca}, \mathrm{Mg}, \mathrm{P}$ e $\mathrm{K})$ e, conseqüentemente, soma de bases (SB), capacidade de troca de cátions (CTC) e saturação por bases (V\%), além de menor teor de alumínio $(\mathrm{Al})$ e acidez $(\mathrm{pH})$ fraca (figura 6, tabela 6). Dessa forma, observamos que a maioria dos indivíduos das cinco espécies está associada às cinco amostras de solo com menor fertilidade (pontos 2, 3, 4, 5 e 6). Poucos indivíduos ocorrem espacialmente próximos ao ponto 1 , sendo basicamente os indivíduos das classes diamétricas intermediárias (classes 3, 4 e 5) de B. purpurascens, $Q$. grandiflora e $Q$. multiflora (figura 6).

\section{Discussão}

Estrutura diamétrica - O padrão de distribuição diamétrica em forma de "J-invertido" mostra que as cinco populações analisadas possuem representantes em todas as classes de tamanho, porém, com maior densidade nas classes menores. Segundo Silva Júnior (2004), o padrão "J-invertido" indica um balanço positivo entre recrutamento e mortalidade, sendo característico de populações auto-regenerativas, uma vez que tal padrão só ocorre quando os indivíduos menores substituem, sucessivamente, os indivíduos adultos na população. Nesse sentido, a distribuição diamétrica mais balanceada de $C$. americana, $Q$. grandiflora e $Q$. multiflora indica que tais espécies possuem um bom equilíbrio entre mortalidade e crescimento, considerando as seis classes diamétricas estabelecidas nesse estudo.

Por outro lado, o oposto é verificado para $B$. purpurascens e $P$. rotundifolia. As irregularidades na frequência das classes diamétricas sugerem certo desequilíbrio entre mortalidade e recrutamento. Segundo Felfili \& Silva Júnior (1988), a interpretação das medidas de diâmetros em histogramas de frequência de classes pode indicar possíveis perturbações passadas, naturais ou antrópicas, como explorações madeireiras, abates seletivos, incêndios, desmatamentos e herbivoria. Estes eventos aparecem como interrupções nos histogramas, indicando que o ciclo de vida das espécies não estaria se completando (Felfili \& Silva Júnior 1988).

Assim, as oscilações na frequência das classes diamétricas dessas duas populações (B. purpurascens e $P$. rotundifolia) sugerem aumento na mortalidade de plântulas no passado, evidenciado pela baixa frequência de indivíduos na segunda e terceira classes (e na quarta classe somente para B. purpurascens) em relação à imediata classe superior. Tal irregularidade indica uma interrupção no fluxo proporcional de 

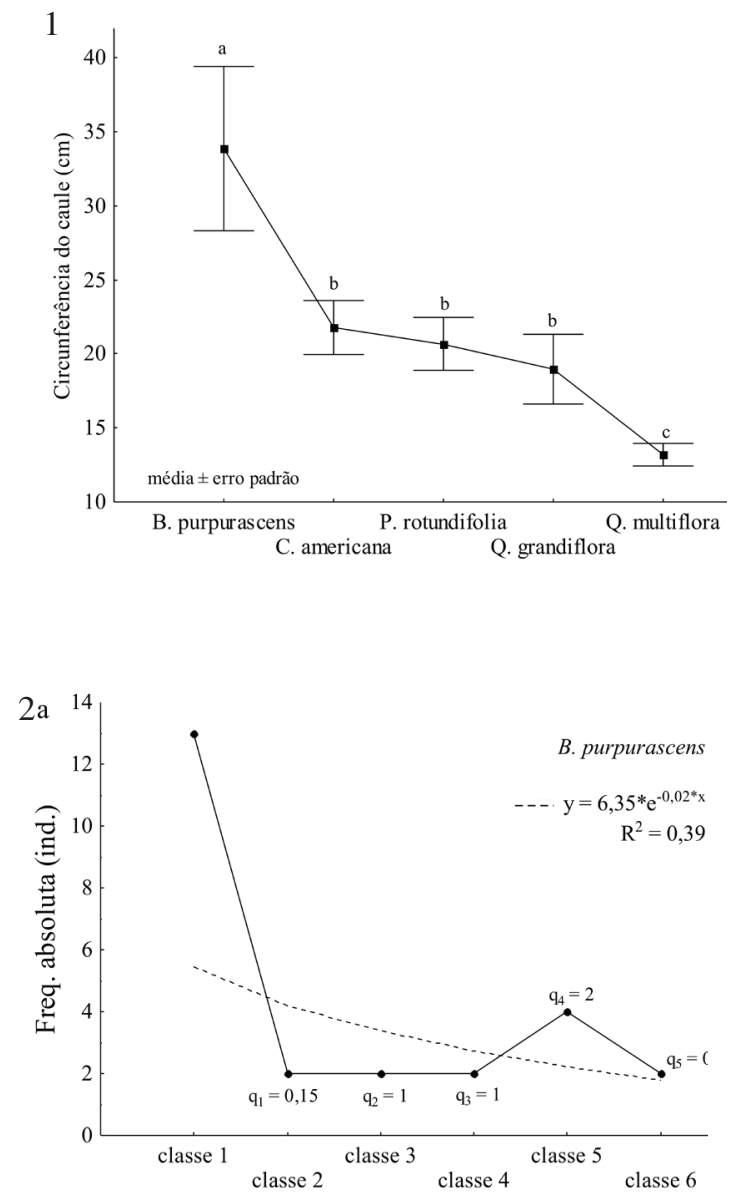

Classes diamétricas

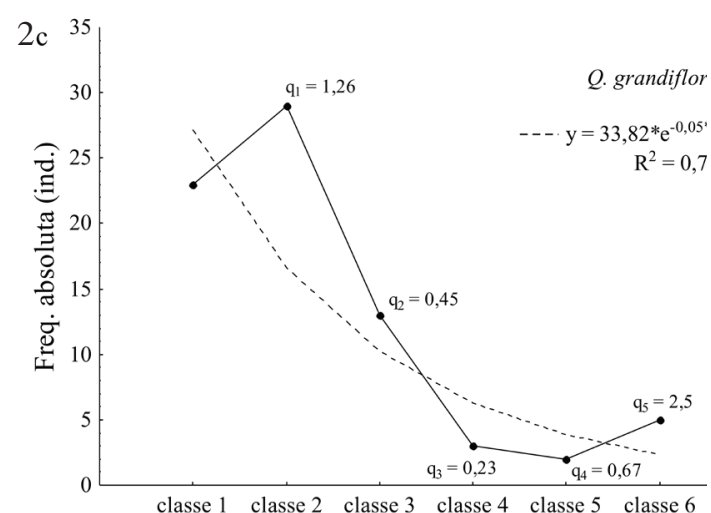

Classes diamétricas

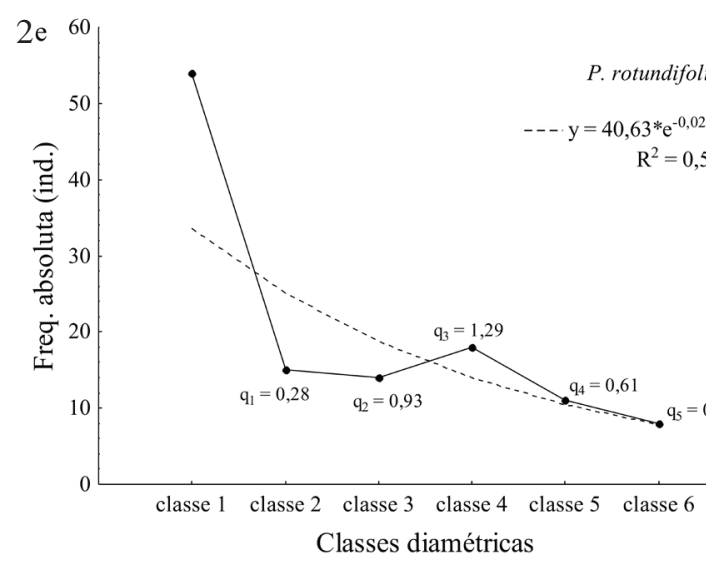

Figura 1. Média \pm erro padrão da circunferência do caule de cinco espécies em um cerrado sentido restrito estudadas no $41^{\circ}$ BIMtz, Jataí, Goiás, Brasil. Médias seguidas de mesma letra não se diferem ao nível de significância de $5 \%$ pelo teste "t".

Figure 1. Mean \pm standard error of stem circumference for tree species of Cerrado sensu stricto analysed in the $41^{\circ}$ BIMtz, Jataí, Goiás, Brazil. Means with same letters not differ at significance level of $5 \%$ by " $t$ " test.

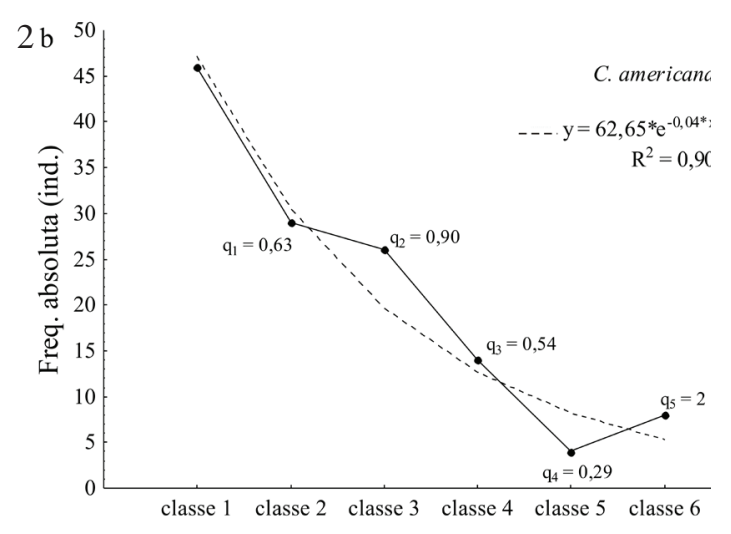

Classes diamétricas

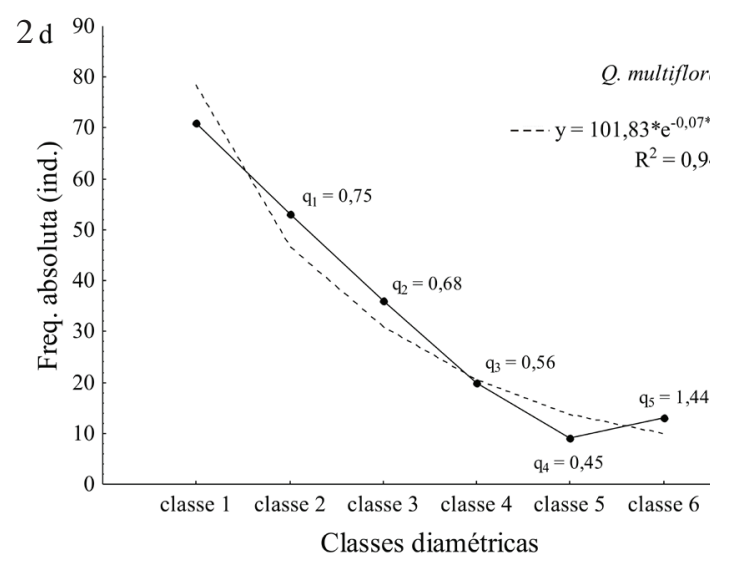

Figura 2. Distribuição de frequência dos indivíduos nas classes diamétricas, coeficiente de Liocourt $(\mathrm{q})$ e coeficiente de determinação $\left(\mathrm{R}^{2}\right)$ para as cinco espécies arbóreas do cerrado sentido restrito estudadas no $41^{\circ}$ BIMtz, Jataí, Goiás, Brasil. A linha contínua representa as frequências observadas e a linha tracejada, o ajuste à curva "J-invertido" (função exponencial negativa: $\left.\mathrm{y}=\mathrm{e}^{-\mathrm{x}}\right)$.

Figure 2. Frequency distribution of individuals on the size classes, Liocourt coefficient (q) and coeffincient of determination $\left(\mathrm{R}^{2}\right)$ for tree species of Cerrado sensu stricto analysed in the $41^{\circ}$ BIMtz, Jataí, Goiás, Brazil. Solid and dashed line indicate the frequencies observed and reverse J-shaped adjust (negative exponential function: $\mathrm{y}=\mathrm{e}^{-\mathrm{x}}$ ). 

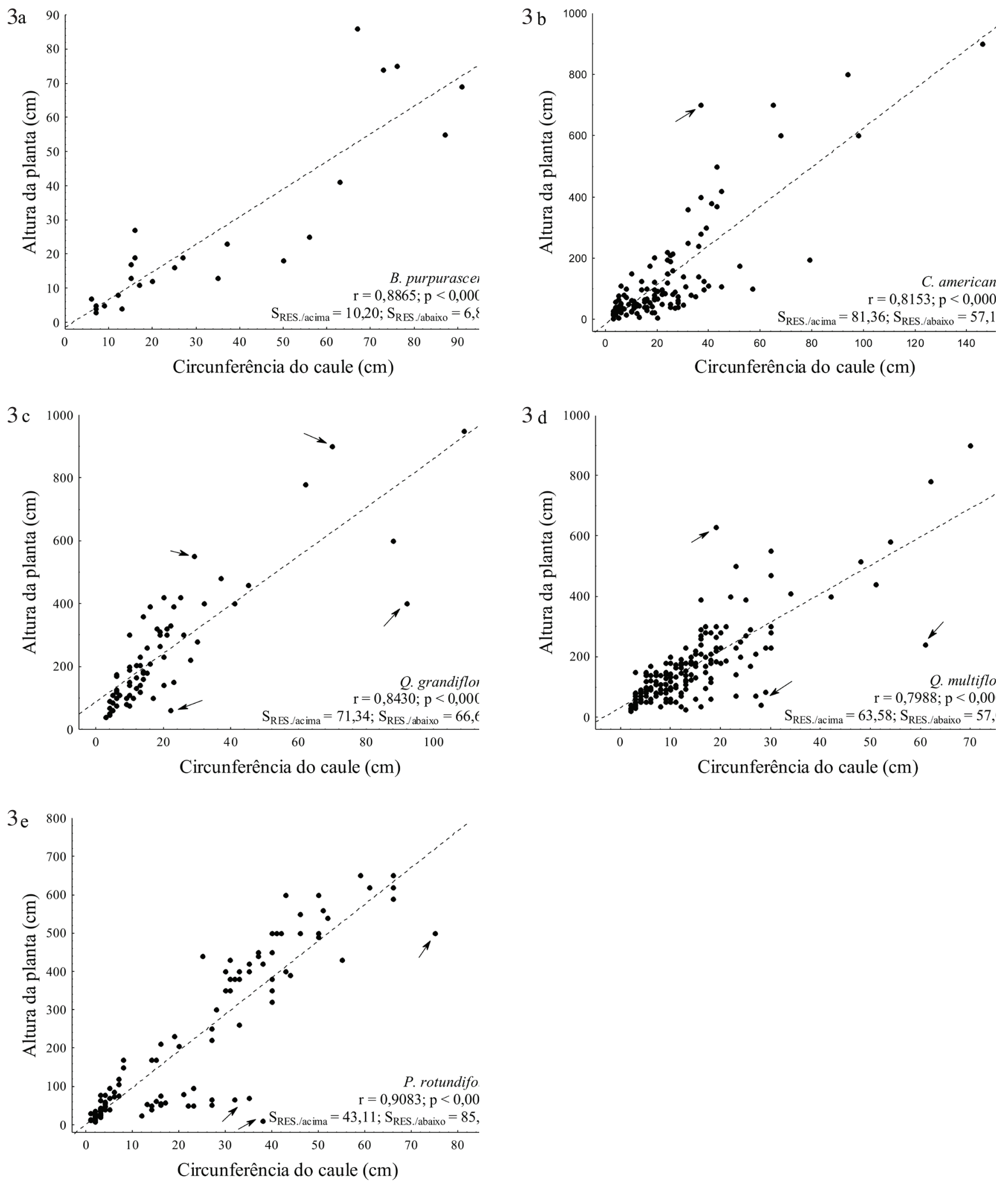

Figura 3. Relação entre a circunferência do caule e a altura da planta para as cinco espécies arbóreas do cerrado sentido restrito estudadas no $41^{\circ}$ BIMtz, Jataí, Goiás, Brasil. A linha tracejada indica o ajuste linear entre as variáveis e as setas indicam valores extremos ("outliers") ao ajuste linear. $\mathrm{S}_{\mathrm{RES} / \text { acima }}$ e $\mathrm{S}_{\mathrm{RES} \text {.abaixo }}$ indicam, respectivamente, o desvio padrão dos resíduos referentes aos pontos acima e abaixo do ajuste linear.

Figure 3. Linear relationship between stem circumference and individual height for tree species of Cerrado sensu stricto analysed in the $41^{\circ}$ BIMtz, Jataí, Goiás, Brazil. Dashed line indicate the liner fit between the variables and arrows indicate outliers at the linear fit. $\mathrm{S}_{\mathrm{RES} . /}$ acima and $\mathrm{S}_{\mathrm{RES} / \text { /abaixo }}$ indicate the standard deviation of above and below points at the linear fit. 

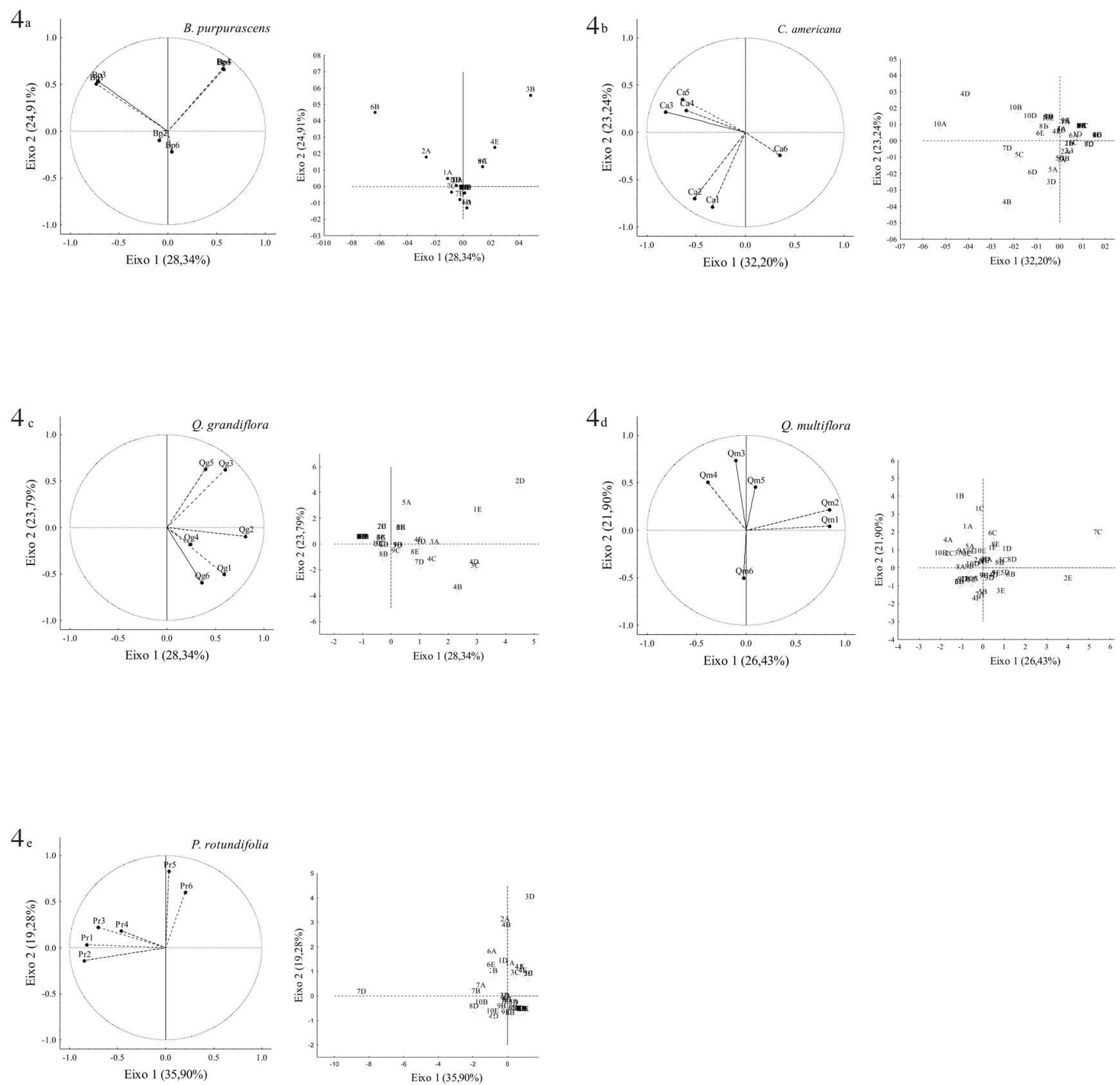

Figura 4. Análise de Componentes Principais (PCA) com os coeficientes de correlação de Pearson (à esquerda) e escores (à direita), evidenciando a ordenação das classes de tamanho para cada uma das cinco espécies arbóreas do cerrado sentido restrito estudadas no $41^{\circ}$ BIMtz, Jataí, Goiás, Brasil. Nas figuras à esquerda, as linhas tracejadas representam a ordenação das seis classes de tamanho para cada espécie analisada; e nas figuras à direita, os pontos representam as parcelas na área de estudo. As variâncias acumuladas (\%) pelo primeiro e segundo eixo da PCA estão descritas em cada figura. $\mathrm{Bp}=$ Butia purpurascens; $\mathrm{Ca}=$ Curatella americana $; \mathrm{Pr}=$ Piptocarpha rotundifolia; $\mathrm{Qg}=$ Qualea grandiflora, $\mathrm{Qm}=$ Qualea multiflora

Figure 4. Principal components analises (PCA) ordination of the size classes for each tree species of Cerrado sensu stricto analyzed in the $41^{\circ}$ BIMtz, Jataí, Goiás, Brazil. At left figures, the dashed lines indicate the size classes' ordination for each tree species and at right figures, the points indicates the quadrats on the study area. The variances accumulated (\%) on the first and second axes are on figures. $\mathrm{Bp}=$ Butia purpurascens $; \mathrm{Ca}=$ Curatella americana $; \mathrm{Pr}=$ Piptocarpha rotundifolia $; \mathrm{Qg}=$ Qualea grandiflora, $\mathrm{Qm}=$ Qualea multiflora . 

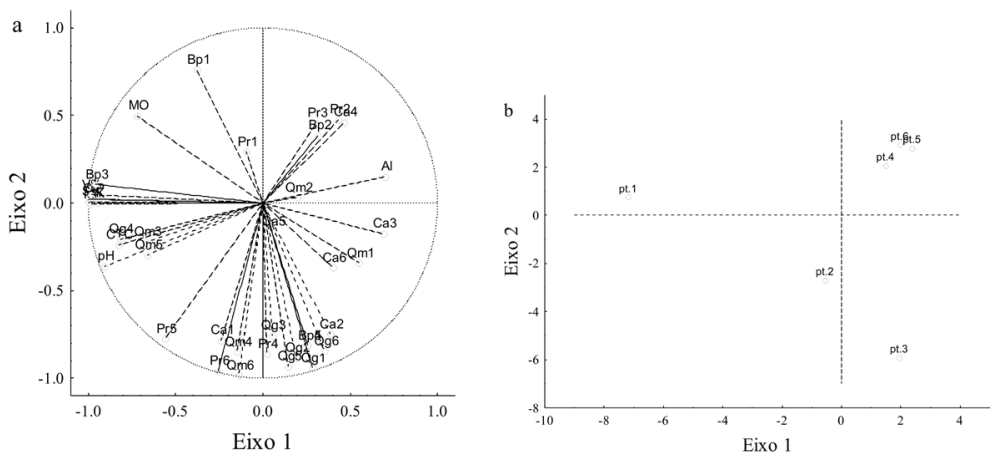

Figura 5. Análise de Componentes Principais (PCA) com os coeficientes de correlação de Pearson (a) e escores (b), evidenciando a ordenação das classes de tamanho simultaneamente para as cinco espécies arbóreas do cerrado sentido restrito estudadas no 41 ${ }^{\circ}$ BIMtz, Jataí, Goiás, Brasil. Em (a), as linhas tracejadas representam a ordenação das seis classes de tamanho para as cinco espécies analisadas; e em (b), os pontos representam as parcelas na área de estudo. $\mathrm{Bp}=$ Butia purpurascens $; \mathrm{Ca}=$ Curatella americana; $\mathrm{Pr}=$ Piptocarpha rotundifolia; $\mathrm{Qg}=$ Qualea grandiflora e $\mathrm{Qm}=$ Qualea multiflora . Os números $1,2, \ldots, 6$ representam as seis classe de tamanho. O primeiro e o segundo eixos da PCA acumularam $10,70 \%$ e $8,76 \%$ da variância total, respectivamente.

Figure 5. Principal components analises (PCA) ordination of the size classes for all tree species, simultaneously, of Cerrado sensu stricto analyzed in the $41^{\circ}$ BIMtz, Jataí, Goiás, Brazil. In (a), the dashed lines indicate the size classes' ordination for all tree species and in (b), the points indicates the quadrats on the study area. $\mathrm{Bp}=$ Butia purpurascens; $\mathrm{Ca}=$ Curatella americana; $\mathrm{Pr}=$ Piptocarpha rotundifolia; $\mathrm{Qg}=$ Qualea grandiflora and Qm $=$ Qualea multiflora. The numbers $1,2, \ldots, 6$ indicates the six size classes. The first and second PCA axes accumulated $10,70 \%$ and $8,76 \%$ of the total variance, respectively.
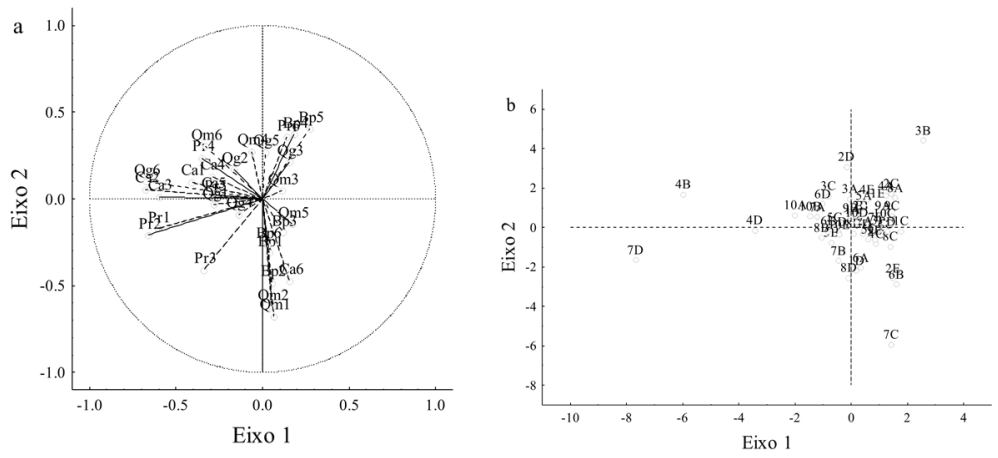

Figura 6. Análise de Componentes Principais (PCA) com os coeficientes de correlação de Pearson (a) e escores (b), evidenciando a ordenação das classes de tamanho das cinco espécies arbóreas e dos elementos indicativos de fertilidade do solo do cerrado sentido restrito estudadas no $41^{\circ}$ BIMtz, Jataí, Goiás, Brasil. Em (a), as linhas tracejadas representam a ordenação classes de tamanho e dos elementos de fertilidade do solo; e em (b), os pontos representam as amostras de solo. Elementos do solo $(\mathrm{Al}=$ alumínio; $\mathrm{Ca}=$ cálcio; $\mathrm{Mg}=$ magnésio; $\mathrm{K}=$ potássio; $\mathrm{P}=$ fósforo; $\mathrm{pH}=$ acidez; $\mathrm{MO}=$ matéria orgânica; $\mathrm{SB}=$ soma de bases trocáveis; $\mathrm{CTC}=$ capacidade de troca de cátions e $\mathrm{V} \%=$ saturação por bases); espécies ( $\mathrm{Bp}=$ Butia purpurascens; $\mathrm{Ca}=$ Curatella americana; $\mathrm{Pr}$ = Piptocarpha rotundifolia $; \mathrm{Qg}=$ Qualea grandiflora $; \mathrm{Qm}=$ Qualea multiflora $)$. Os números 1, 2,..., 6 representam as seis classe de tamanho. O primeiro e o segundo eixos da PCA acumularam 34,53\% e 32,57\% da variância total, respectivamente.

Figure 6. Principal components analises (PCA) ordination of the size classes for all tree species and the chemical elements indicative of ground fertility of Cerrado sensu stricto analyzed in the $41^{\circ}$ BIMtz, Jataí, Goiás, Brazil. In (a), the dashed lines indicate the ordination of the size classes for all tree species and chemical elements, and in (b), the points indicates the ground samples. $\mathrm{Al}=\mathrm{aluminium}, \mathrm{Ca}$ = calcium, $\mathrm{Mg}=$ magnesium, $\mathrm{K}=$ potassium, $\mathrm{P}=$ phosphorus, $\mathrm{pH}=$ acidity, $\mathrm{MO}=$ organic matter, $\mathrm{SB}=$ changeable basis sum, $\mathrm{CTC}=$ capacity of cations change, $\mathrm{V} \%=$ basis saturation. $\mathrm{Bp}=$ Butia purpurascens; $\mathrm{Ca}=$ Curatella americana; $\mathrm{Pr}=$ Piptocarpha rotundifolia; $\mathrm{Qg}=$ Qualea grandiflora e $\mathrm{Qm}=$ Qualea multiflora . The numbers 1,2, .., 6 indicates the six size classes. The first and second PCA axes accumulated $34,53 \%$ and $32,57 \%$ of the total variance, respectively.

indivíduos que ocupariam essas classes intermediárias atualmente pelo crescimento dos indivíduos e sugere que as populações de $B$. purpurascens e $P$. rotundifolia são mais suscetíveis às variações e perturbações ambientais que $C$. americana, $Q$. grandiflora e $Q$. multiflora, principalmente aquelas provocadas pelas ações antrópicas. Por outro lado, a elevada proporção de indivíduos na primeira classe de tamanho indica que tais perturbações cessaram e que as populações de $B$. purpurascens e $P$. rotundifolia estão em fase de restabelecimento na área de estudo ou que, se ainda existem, influenciam negativamente os indivíduos apenas no estádio intermediário de desenvolvimento: após o estádio de plântula, mas antes de se tornarem adultos.

Fidelis \& Godoy (2003) argumentam que a maior concentração de indivíduos nas primeiras classes de tamanho, segundo o padrão "J-invertido", pode ser explicada pela própria potencialidade genética da maioria das espécies de cerrado, as quais apresentam indivíduos de pequeno porte, mesmo quando adultos. No entanto, o mesmo padrão é observado para a maioria das espécies de florestas tropicais de grande porte que apresentam indivíduos bem desenvolvidos (Harper 1990). Ainda, o argumento de Fidelis \& Godoy (2003) não se aplica aos nossos resultados, uma vez que os critérios utilizados para calcular a amplitude das classes (média e desvio padrão da circunferência do caule) excluem a influência de fatores indesejáveis, como o porte das espécies. Dessa forma, isso só poderia ocorrer caso a amplitude das classes de tamanho fossem fixas para todas as espécies estudadas.

Além disso, evidências semelhantes também são 
sugeridas pela relação entre a circunferência do caule e a altura da planta quanto à suscetibilidade das cinco espécies às variações e perturbações ambientais. A maior proporção de indivíduos com elevada altura, porém com caules relativamente finos (pontos distantes e acima do ajuste linear), também sugere que $C$. americana, $Q$. grandiflora e $Q$. multiflora possuem alta capacidade de regeneração frente aos fatores perturbadores, influenciando positivamente a taxa de recrutamento na população.

Por outro lado, a proporção relativamente alta de indivíduos com caules bem desenvolvidos quando comparados à altura (pontos distantes e abaixo do ajuste linear), sugerem que $P$. rotundifolia, provavelmente, seja mais suscetível aos fatores perturbadores que danificam os indivíduos, prejudicando seu desenvolvimento. Assim, indivíduos bem desenvolvidos, quando danificados, apresentam troncos quebrados com brotos laterais. Isso influencia a dinâmica da população, uma vez que os indivíduos adultos deixam de reproduzir durante a fase de recuperação (rebrota), diminuindo, conseqüentemente, a densidade de indivíduos em certas classes de tamanho. A presença de indivíduos também nessas condições para as duas espécies do gênero Qualea sugere certo equilíbrio entre capacidade de regeneração e, conseqüentemente, recrutamento, e suscetibilidade às pressões perturbadoras. Segundo Lorenzi (1998), essas espécies rebrotam com facilidade após a queima.

De acordo com Miranda \& Sato (2005), o rebrotamento lateral é comum em espécies lenhosas do Cerrado após freqüentes queimadas e indica uma estratégia de resistência frente a perturbações. Além disso, o fogo também é estreitamente ligado à alta taxa de crescimento da planta em altura (Hoffmann \& Moreira 2002). Logo, sugere-se que o padrão observado com relação à circunferência do caule $\mathrm{e}$ altura da planta para $Q$. grandiflora, $Q$. multiflora e $P$. rotundifolia seja causado pelo rebrotamento, estimulado pelo fogo (origem antrópica ou natural), o qual ocorre com frequência na área de estudo.

Segundo Higgins et al. (2000), árvores de savanas sujeitas a queimadas somente recrutam indivíduos juvenis à adultos se escaparem da zona de influência do fogo. Logo, a habilidade do caule aéreo de rebrotar após ser queimado é uma característica da história de vida que é chave para promover a persistência de árvores em savanas sujeitas a incêndios frequientes. No entanto, a frequência de escape do fogo de juvenis rebrotados depende da taxa de crescimento do caule, principalmente em áreas com fogo freqüente
(Higgins et al. 2000). Desse modo, os resultados para C. americana sugerem que o crescimento estimulado pelo fogo possivelmente tenha alguma influência na determinação da forma de seus indivíduos, verificado pelo maior número de indivíduos com altura relativamente superior à circunferência do caule. $B$. purpurascens não apresentou variação extrema ao ajuste linear na relação circunferência do caule e altura da planta, devido, provavelmente, ao fato de ser uma palmeira e não apresentar perfilhamento. No entanto, é necessário que essas populações sejam acompanhadas ao longo do tempo para que se possam determinar os fatores influentes na dinâmica populacional.

Em geral, embora as espécies analisadas apresentem distribuição diamétrica seguindo o padrão geral em forma de "J-invertido" e uma alta correlação entre circunferência do caule e altura da planta, os dados indicam diferenças no padrão estrutural das cinco populações e, conseqüentemente, nos processos de estruturação e dinâmica de cada espécie. Resumindo, C. americana, Q. grandiflora e $Q$. multiflora possuem maior equilíbrio entre mortalidade e crescimento na área estudada que B. purpurascens e $P$. rotundifolia e, portanto, são menos influenciadas pelas perturbações ambientais, principalmente aquelas de origem antrópica.

Distribuição espacial - A distribuição agrupada é verificada naturalmente quando, em parcelas semelhantes, o número de indivíduos varia fortemente de uma parcela a outra, a ponto de formarem conjuntos de parcelas de acordo com a densidade de indivíduos (Greig-Smith 1964, Kershaw 1973, Mueller-Dombois \& Ellenberg 1974, Barbour et. al. 1987). O máximo de agrupamento seria verificado se todos os indivíduos de cada espécie ocorressem em uma única parcela (ou unidade amostral). Neste caso, esperar-se-ia que os valores da razão variância/ média ( $I$ ) e do coeficiente de Green (Ig) fossem iguais ao número de indivíduos na população e um, respectivamente (Ludwig \& Reynolds 1988, Krebs 1999). Portanto, os valores encontrados para esses índices de dispersão ( $I$ e $I g$ ) indicam baixo grau de agrupamento para as cinco populações, apesar do padrão de distribuição espacial revelar-se agregado, conforme $\mathrm{o}$ ajuste significativo às frequências esperadas pela Distribuição Binomial Negativa.

O padrão de distribuição espacial agregado pode ser influenciado, a priori, pelo acúmulo de grandes quantidades de sementes em determinadas porções espaciais (micro-sítios), enquanto outros micro- 
sítios apresentariam baixas densidades de sementes ou densidade nula. Assim, espera-se que as taxas de germinação e recrutamento sejam maiores nos micro-sítios com acúmulo de sementes em relação aos outros ambientes e, portanto, os indivíduos apresentar-se-iam agregados no espaço (Barbour et. al. 1987). Nesse caso, a estrutura espacial agregada seria característica de espécies vegetais cujas sementes são dispersas por animais (zoocoria) ou que realizam sua dispersão por autocoria (barocoria, Greig-Smith 1964). As sementes dessas espécies são acumuladas, muitas vezes, por serem expelidas com as fezes (zoocoria) ou cairem, por ação da gravidade, sob a copa da planta que as produziram (barocoria). É o que sugere para $C$. americana, que possui seus propágulos dispersos por aves (Lorenzi 2000a) e para $B$. purpurascens, que realiza sua dispersão por autocoria (Lorenzi 1996).

Por outro lado, Q. grandiflora, Q. multiflora e $P$. rotundifolia possuem dispersão de sementes por anemocoria (Lorenzi 1998, 2000b). Para uma espécie cujos diásporos são dispersos pelo vento, é esperado que a distribuição das sementes sobre o substrato ocorra ao acaso, uma vez que não há deposição proposital de diásporos em determinados microsítios e, conseqüentemente, os indivíduos apresentem padrão de distribuição aleatório. No entanto, os dados obtidos no presente estudo também mostram um padrão de distribuição espacial agregado para essas espécies. Dessa forma, espera-se que outros fatores estejam influenciando o estabelecimento das plântulas e o recrutamento dos indivíduos em determinados micro-sítios nessa área. Tais fatores podem se originar de processos naturais (bióticos e abióticos) e/ou antrópicos (Greig-Smith 1964, Kershaw 1973, Mueller-Dombois \& Ellenberg 1974, Barbour et. al. 1987).

Estudos apontam que as queimadas promovem diferentes tipos de danos e influências na dinâmica populacional, principalmente nos padrões reprodutivos (como intensidade e sazonalidade de floração, produção de frutos e sementes), no recrutamento e estabelecimento de novos indivíduos (como sobrevivência de plântulas e indivíduos jovens) e na taxa de mortalidade (indivíduos adultos e sobrevivência de rebrotas) (Hoffmann \& Moreira 2002). Dessa forma, a estruturação populacional é influenciada de diferentes maneiras ao longo do espaço por ocorrência diferencial do fogo e herbivoria em diferentes micro-sítios, promovendo a agregação dos indivíduos de espécies e classes de tamanho distintas nos locais mais propícios à sua sobrevivência (Henriques 2005). As populações analisadas provavelmente estão se estruturando espacialmente sob influência de tais fatores antrópicos, uma vez que esta área apresenta-se fragmentada e seu histórico indica freqüente recorrência de queimadas (de origem antrópica com frequência anual ou bienal), utilização para pastagem e extrativismo seletivo. Os indivíduos adultos freqüentemente apresentam troncos queimados com rebrota lateral. Outras evidências da perturbação antrópica na dinâmica dessas populações foram discutidas quanto à estrutura diamétrica, no item anterior.

Dentre os fatores ambientais, o substrato (fator abiótico) é um dos mais importantes na determinação da estruturação espacial das populações vegetais (Greig-Smith 1964, Kershaw 1973, Mueller-Dombois \& Ellenberg 1974, Barbour et. al. 1987). Por um lado, as variações fitofisionômicas do bioma Cerrado, bem como a distribuição geográfica de algumas espécies vegetais, são diretamente influenciadas pela heterogeneidade das condições edáficas como idade, textura, profundidade, fertilidade e disponibilidade hídrica do solo (Haridasan 2005). Por outro lado, a heterogeneidade local influencia a distribuição espacial dos indivíduos em escalas menores (populações, por exemplo), uma vez que o estabelecimento das plantas se dá conforme as características do substrato propícias ao seu desenvolvimento. Dessa forma, caso o solo de uma região apresente manchas locais com características físicas e químicas diferentes, as populações vegetais estruturam-se da mesma maneira, apresentando, portanto, indivíduos agregados no espaço (Barbour et. al. 1987).

$\mathrm{Na}$ área de estudo, os dados indicam que as cinco populações estudadas apresentam-se estruturadas também sob influência da fertilidade do solo. A ocorrência preferencial dos indivíduos nas parcelas com solo menos fértil, indicada na ordenação multivariada (PCA), corrobora os padrões observados para o cerrado sentido restrito, cujas espécies são adaptadas a condições edáficas de menor disponibilidade de nutrientes (Henriques 2005). Também indica que os grupos de indivíduos das populações estudadas ocorrem em manchas de solo com características peculiares, seja com menor fertilidade (maioria dos indivíduos das cinco espécies) ou maior fertilidade (indivíduos de B. purpurascens, $Q$. grandiflora e $Q$. multiflora das classes de tamanho intermediárias), embora as diferenças quantitativas 
dos nutrientes sejam pequenas entre os pontos. No entanto, segundo Henriques (2005), quando as características edáficas mudam expressivamente entre áreas distintas, a fitofisionomia também muda.

As interações positivas entre indivíduos da mesma espécie são outro grupo de fatores ambientais (bióticos) que também promovem a agregação dos mesmos em uma população (Odum 1988, Ricklefs 2003). Ao contrário, a estruturação espacial disjunta dos indivíduos adultos e juvenis de $B$. purpurascens, $C$. americana, $Q$. multiflora e $P$. rotundifolia indicada na ordenação das classes de tamanho pela PCA, sugere a influência da competição intra-específica entre os indivíduos das diferentes classes de tamanho e da predação (interações negativas) na estruturação espacial das populações. Segundo Crawley (1997), o recrutamento ocorre dentro da sombra de sementes, sob influência dos fatores edáficos e de duas variáveis ecológicas: competição e predação. Harper (1990) descreve esta fase como sendo a peneira ambiental, em que a presença ou ausência de plântulas não depende apenas da quantidade de sementes, mas também de locais seguros que propiciem as condições necessárias para o desenvolvimento de cada semente, conferido pela sobrevivência e crescimento das plântulas.

Odum (1988) afirma que várias espécies vegetais apresentam maior densidade de plântulas longe da planta mãe devido à influência da competição intra-específica. Segundo o autor, maiores taxas de germinação das sementes e desenvolvimento das plântulas ocorrem fora da área de influência direta da planta mãe, onde a taxa de luminosidade e as condições edáficas são mais propícias, uma vez que as plântulas são competitivamente inferiores aos adultos. Nesse mesmo sentido, o modelo de Janzen-Connell prediz que a predação de sementes e plântulas ocorre com maior intensidade próxima aos indivíduos adultos, onde a densidade de sementes e plântulas é maior num primeiro momento (hipótese da fuga, Janzen 1970, Connell 1971).

Além disso, Augspurger (1983) considerou mais uma hipótese para explicar as vantagens da dispersão em relação à planta mãe: "a hipótese da colonização". Segundo o autor, essa hipótese sugere que a dispersão aumenta a probabilidade de alguma parte da progênie ir parar em locais de perturbações no ambiente, como clareiras, que aumentam a chance de estabelecimento e sobrevivência das plântulas. A probabilidade de uma clareira ocorrer dentro da área de dispersão de uma planta-mãe aumenta com o aumento da distância de dispersão (Augspurger 1983).
Dessa maneira, tais fatores fazem com que o recrutamento ocorra preferencialmente longe de indivíduos adultos, o que promoveria a agregação espacial dos juvenis. Ainda, o resultado dos modelos previstos pelas hipóteses "da Fuga" e "da Colonização" fica evidenciado nas populações de $B$. purpurascens, $C$. americana, $Q$. multiflora e $P$. rotundifolia e, provavelmente, atuante no processo de estruturação espacial das mesmas.

Janzen (1970) afirma, ainda, que o padrão de recrutamento oriundo do modelo de JanzenConnell (hipótese da fuga) para predação de sementes, contribui para que as diferentes espécies se estabeleçam na mesma redondeza, o que em parte explicaria a associação entre os indivíduos menores de $C$. americana e maiores de $Q$. grandiflora e $Q$. multiflora e vice-versa, mesmo na ausência de interações positivas entre essas espécies. Por outro lado, a associação entre os indivíduos juvenis e adultos de apenas três das cinco espécies analisadas, sugere alguma interação positiva entre $C$. americana e as duas espécies do gênero Qualea, em que a presença de indivíduos adultos de uma das espécies favoreça o estabelecimento e desenvolvimento de juvenis da outra espécie.

Finalizando, a estrutura espacial agregada dessas cinco populações corrobora com o padrão geral encontrado em outros estudos e revela-se dominante entre as espécies vegetais do Cerrado em diferentes escalas e fitofisionomias (Oliveira et al. 1989, Meireles \& Luiz 1995, Hay et al. 2000, Resende et al. 2003, Souza \& Coimbra 2005, Costa 2006, LimaRibeiro 2007a, b, Lima-Ribeiro \& Prado 2007). Além disso, o estudo evidencia influência do substrato no padrão de distribuição espacial dos indivíduos e sugere associação entre as espécies analisadas.

\section{Agradecimentos}

Agradecemos ao Prof. Frederico A. G. Guilherme e à Profa. Kaila de A. Ressel Pereira pelos comentários ao manuscrito, ao Exército Brasileiro pela concessão da licença de pesquisa e atividades acadêmicas na Reserva Biológica do $41^{\circ}$ Batalhão de Infantaria Motorizado de Jataí e aos funcionários do Laboratório de Solos do Campus Jataí/UFG pela análise das amostras de solo. Este trabalho foi suportado, em parte, com recursos do PROAPI/CAJ (edital 01/2008). 


\section{Literatura citada}

Aquino, F.G., Walter, B.M.T. \& Ribeiro, J.F. 2007. Dinâmica de populações de espécies lenhosas de Cerrado, Balsas, Maranhão. Revista Árvore 31: 793-803.

Augspurger, C.K. 1983. Offspring recruitment around tropical trees: changes in cohort distance with time. Oikos 40: 189-196.

Barbour, M.G., Burk, J.H. \& Pitts, W.D. 1987. Terrestrial Plant Ecology. 2 ed. Benjamim/ Cummings, Menlo-Park.

Barreira, S., Scolforo, J.R.S., Botelho, S.A. \& Mello, J.M. 2002. Estudo da estrutura da regeneração natural e da vegetação adulta de um cerrado sensu stricto para fins de manejo florestal. Scientia Forestalis 61: 64-78.

Bongers, F., Pompa, J., Meave-Del Castillo, J. \& Carabias, J. 1988. Structure and floristic composition of the lowland rain forest of Los Tuxtlas, Mexico. Vegetatio 74: 55-80.

Connel, J.H. 1971. On the role of natural enemies in preventing competitive exclusion in some marine animals and in rain Forest trees. In: P.J. Den Böer \& G.R. Gradwell (eds.). Dynamics of populations. Center for Agricultural Publications and Documentation, Wagenigen.

Costa, C.R. 2006. Distribuição espacial e relações alométricas de espécies de Vochysiaceae em fragmentos de cerrado no município de Itirapina, São Paulo. Dissertação de Mestrado, Universidade Estadual de Campinas, Campinas.

Crawley, M.J. 1997. Plant ecology. Blackwell Sciences, London.

Eiten,G. 1994. Vegetação do cerrado. In: M.N Pinto (ed.). Cerrado: Caracterização, ocupação e perspectivas. SEMATEC, Brasília, pp. 17-74.

Felfili, J.M. \& Silva Júnior, M.C. 1988. Distribuição dos diâmetros numa faixa de cerrado na Fazenda Água Limpa (FAL) em Brasília, DF. Acta Botanica Brasilica 2: 85-104.

Fidelis, A.T. \& Godoy, S.A.P. 2003. Estrutura de um cerrado stricto sensu na gleba cerrado Pé-deGigante, Santa Rita do Passa Quatro, SP. Acta Botanica Brasilica 17: 531-539.

Fortin, M.J., Dale, M.R.T. \& Hoef, J. 2002. Spatial analysis in ecology. In: A.H. El-Shaarawi \& W.W. Piegorsch (eds.). Encyclopedia of Environmetrics. John Wiley \& Sons, Chichester, pp. 2051-2058.

Greig-Smith, M.A.P. 1964. Quantitative Plant
Ecology. 2 ed. Buther Worths, London.

Haridasan, M. 2005. Competição por nutrientes em espécies arbóreas do cerrado. In: J.C. SouzaSilva \& J.M. Felfili (orgs.). Cerrado: Ecologia, biodiversidade e conservação. Ministério do Meio Ambiente, Brasília, pp. 73-92.

Harper, J.L. 1990. Population biology of plants. Academic Press, London.

Hay, J.D., Bizerril, M.X., Calouro, A.M., Costa, E.M.N., Ferreira, A.A., Gastal, M.L.A., Goes Junior, C.D., Manzan, D.J., Martins, C.R., Monteiro, J.M.G., Oliveira, S.A., Rodrigues, M.C.M., Seyffarth, J.A.S. \& Walter, B.M.T. 2000. Comparação do padrão da distribuição espacial em escalas diferentes de espécies nativas do cerrado, em Brasília, DF. Revista Brasileira de Botânica 23: 341-347.

Henriques, R.P.B. 2005. Influência da história, solo e fogo na distribuição e dinâmica das fitofisionomias no bioma do Cerrado. In: J.C. Souza-Silva \& J.M. Felfili (orgs.). Cerrado: Ecologia, biodiversidade e conservação. Ministério do Meio Ambiente, Brasília, pp. 7392.

Higgins, S.I., Bond, W.J. \& Trollope, W.S.W. 2000. Fire, resprouting and variability: a recipe for grass-tree coexistence in savanna. Journal of Ecology 88: 213- 29.

Hoffmann, W.A. \& Moreira, A. 2002. The role of fire in population dynamics of woody plants. In: P.S. Oliveira \& R.S. Marquis (eds.). Ecology and natural history of a neotropical savanna: the cerrados of Brazil. The University of Columbia Press, New York, pp. 159-177.

Hutchings, M.J. 1997. The structure of plant populations. In: M.J. Crawley (ed.). Plant ecology. Blackwell Science, Oxford, pp. 325358.

Janzen, D.H. 1970. Herbivores and the number of tree species in tropical forest. American Naturalist 104: 501-508.

Kershaw, K.A. 1973. Quantitative and dynamic plant ecology. 2 ed. American Elsevier, New York.

Krebs, C.J. 1999. Ecological Methodology. 2. ed. Benjamim/Cummings, Menlo Park.

Legendre, P. \& Fortin, M.J. 1989. Spatial pattern and ecological analysis. Vegetatio 80: 107-138.

Lima-Ribeiro, M.S. 2007a. Distribuição espacial de Duguetia furfuraceae (A. St.-Hil.) Benth. $\&$ Hook. (Annonaceae) em um campo sujo no 
município de Caiapônia, GO, Brasil. Bioscience Journal 23: 96-104.

Lima-Ribeiro, M.S. 2007b. Distribuição espacial de espécies arbóreas em fragmentos de cerrado sentido restrito no planalto central brasileiro GO. Biociências 15: 160-165.

Lima-Ribeiro, M.S. \& Prado, E.C. Distribuição espacial de uma população de Vernonia aurea Mart.exDC.2007. (Asteraceae)emumfragmento de cerradão no município de Caiapônia, GO, Brasil. Bioscience Journal 23: 81-89.

Lorenzi, H. 1996. Palmeiras no Brasil, nativas e exóticas. v. 2. Plantarum, Nova Odessa.

Lorenzi, H. 1998. Árvores brasileiras: manual de identificação e cultivo de plantas arbóreas nativas do Brasil. v. 2. Plantarum, Nova Odessa.

Lorenzi, H. 2000a. Plantas daninhas do Brasil: terrestres, aquáticas, parasitas e tóxicas. Plantarum, Nova Odessa.

Lorenzi, H. 2000b. Árvores brasileiras: manual de identificação e cultivo de plantas arbóreas nativas do Brasil. v. 1. 3 ed. Plantarum, Nova Odessa.

Ludwig, J.A. \& Reynolds, J.F. 1988. Statistical Ecology: a primer on methods and computing. John Wiley \& Sons, New York.

Mariano, Z.F. \& Scopel, I. 2001. Períodos de deficiências e excedentes hídricos na região de Jataí/GO. In: Anais do $12^{\circ}$ Congresso Brasileiro de Agrometeorologia, III Reunião LatinoAmericana de Agrometeorologia, Fortaleza, pp. 333-334.

Meireles, M.L. \& Luiz, A.J.B. 1995. Padrões espaciais de árvores de um cerrado em Brasília, DF. Revista Brasileira de Botânica 18: 185-189.

Meyer, H.A. 1952. Structure, growth and drain in balance uneven-aged forests. Journal of Forest 50: 85-92.

Meyer, H.A., Ricknagel, A.B., Stevenson, D.D. \& Bartoo, R.A. 1961. Forest management. Ronald Press, New York.

Miranda, H.S. \& Sato, M.N. 2005. Efeitos do fogo na vegetação lenhosa do cerrado. In: J.C. SouzaSilva \& J.M. Felfili (orgs.). Cerrado: ecologia, biodiversidade e conservação. Ministério do Meio Ambiente, Brasília, pp. 93-106.

Monteiro, E.A.\& Fisch, S.T.V. 2005. Estrutura e padrão espacial das populações de Bactris setosa Mart. e B. hatschbachii Noblick ex A. Hend (Arecaceae) em um gradiente altitudinal, Ubatuba (SP). Biota Neotropica 5: 111-117.
Mueller-Dombois, D. \& Ellenberg, H. 1974. Aims and methods of vegetation ecology. John Wiley \& Sons, New York.

Nimer, E. 1989. Climatologia do Brasil. IBGE, Rio de Janeiro.

Odum, E.P. 198 8. Ecologia. Guanabara Koogan, Rio de Janeiro.

Oliveira, P.E.A.M., Ribeiro, J.F. \& Gonzales, M.I. 1989. Estrutura e distribuição espacial de uma população de Kielmeyera coriacea Mart. de cerrados de Brasília. Revista Brasileira de Botânica 2: 39-47.

Oliveira Filho, A.R. \& Ratter, J.A. 2002. Vegetation physiognomies and woody flora of the Cerrado biome. In: P.S. Oliveira \& R.S. Marquis (eds.). Ecology and natural history of a neotropical savanna: the cerrados of Brazil. The University of Columbia Press, New York, pp. 91-120.

Ratter, J.A., Bridgewater, S. \& Ribeiro, J.F. 2003. Analysis of the floristic composition of the Brazilian cerrado vegetation III: comparison of the woody vegetation of 376 areas. Edinburgh Journal of Botany 60: 57-109.

Resende, J.C.F., Klink, C.A. \& Schiavini, I. 2003. Spatial hererogeneity and its influence on Copaifera langsdorffii Desf. (Caesalpiniaceae). Brazilian Archives of Biology and Technology 46: 405-414.

Ribeiro, J.F. \& Walter, B.M.T. 1998. Fitofisionomias do bioma cerrado. In: S.M. Sano \& S.P. Almeida (eds.). Cerrado: ambiente e flora. EMBRAPACPAC, Planaltina.

Ricklefs, R.E. 2003. A economia da natureza. Guanabara Koogan, Rio de Janeiro.

San Jose, J.J., Farinas, M.R. \& Rosales, J. 1991. Spatial patterns of trees and structuring factors in a Trachypogon savanna of the Orinoco Llanos. Biotropica 23:114-123.

Silva Júnior, M.C. 2004. Fitossociologia e estrutura diamétrica da mata de galeria do Taquara, na reserva ecológica do IBGE, DF. Revista Árvore 28: 419-428.

Silva Júnior, M.C. \& Silva, A.F. 1988. Distribuição dos diâmetros dos troncos das espécies mais importantes do cerrado na estação florestal de experimentação de Paraopeba (EFLEX)- MG. Acta Botanica Brasilica 2: 107-126.

Sokal, R.R. \& Rohlf, F.J. 1995. Biometry: the principles and practice of statistics in biological research. 3. ed. W.H. Freeman, New York.

Souza, J.P. \& Coimbra, F.G. 2005. Estrutura populacional e distribuição espacial de Qualea 
parviflora Mart. em um Cerrado sensu stricto. Bioscience Journal 21: 65-70.

Thomas, C.D. \& Kunin, W.E. 1999. The spatial structure of populations. Journal of Animal Ecology 68: 647-657.

Valentin, J.L. 2000. Ecologia numérica: uma introdução à análise multivariada de dados ecológicos. Interciências, Rio de Janeiro.

Virillo, C.B. 2006. Dinâmica e estrutura de populações de espécies lenhosas no cerrado de Itirapina, SP. Dissertação de Mestrado, Universidade Estadual de Campinas, Campinas.

Zar, J.H. 1999. Statistical analysis. 4 ed. Prentice Hall, New Jersey. 